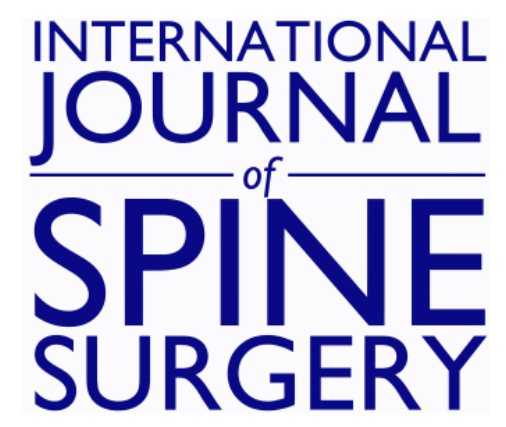

\title{
Radiographic Analysis of Cervical and Spinal Alignment in Multilevel ACDF with Lordotic Interbody Device
}

Yoshihiro Katsuura, Alex Lemons, Eileen Lorenz, Rachel Swafford, James Osborn and Garrick Cason

Int J Spine Surg 2017, 11 (2)

doi: https://doi.org/10.14444/4013

http://ijssurgery.com/content/11/2/13

This information is current as of April 25, 2023.

Email Alerts Receive free email-alerts when new articles cite this article. Sign up at:

http://ijssurgery.com/alerts

The International Journal of Sdoing Surgehth: 2397 Waterbury Circle, Suite 1,

Aurora, IL 60504, Phone: +1-630-375-1432 


\section{Radiographic Analysis of Cervical and Spinal Alignment in Multilevel ACDF with Lordotic Interbody Device}

Yoshihiro Katsuura, MD, ${ }^{1}$ Alex Lemons, MD, ${ }^{1}$ Eileen Lorenz, MD, ${ }^{2}$ Rachel Swafford, $M P H,{ }^{2}$ James Osborn, MD, MPH,1,3 Garrick Cason, MD 1,3

${ }^{1}$ University of Tennessee Department of Orthopaedic Surgery, Chattanooga, TN ${ }^{2}$ Erlanger Hospital, Department of Radiology, Chattanooga, TN ${ }^{3}$ Tennova Health Care, Cleveland, $T N$

\section{Abstract}

\section{Background}

Restoration and maintenance of cervical lordosis is an important clinical parameter in spine surgery. The purpose of this study was to determine the extent to which a multilevel anterior cervical discectomy and fusion (ACDF: greater than 3 levels) procedure restores cervical lordosis and the affect of increasing lordosis on sagittal vertical axis.

\section{Methods}

We performed a retrospective radiographic analysis of 69 patients who underwent multilevel ACDF by 2 surgeons between 2013 and 2014. We measured the global and segmental sagittal alignment of the cervical spine using the cobb method at 4 time intervals (preop, post op 4wks, 10wks and 6 months) as well as the sagittal vertical axis (SVA) using both a C1-S1 and C7-S1 plumb line methods at 2 time intervals (preop and post op 4wks). Radiographs were measured by three reviewers.

\section{Results}

Interrater reliability was good to excellent for all measurements. Cervical lordosis significantly increased from preop $10.26^{\circ}$ to 4 weeks postop $19.44^{\circ}$ and was maintained up to 6 months $19.34(\mathrm{p}<0.0005)$. Segmental cervical lordosis was also significantly increased from preop $8.22^{\circ}$ to post op at 4 weeks $\left(20.26^{\circ}\right)$ and was maintained at post op 10weeks $20.30^{\circ}$ and post op 6 months $19.56^{\circ}$ (p<0.0005). C7-S1 SVA and C1-S1 SVA also significantly increased from $12.04 \mathrm{~mm}$ preop to $27.49 \mathrm{~mm}$ post op 4 wks $(\mathrm{p}<0.0005)$ and $-1.93 \mathrm{~mm}$ preop to $8.67 \mathrm{~mm}$ post op $(\mathrm{p}<0.0005)$ respectively. A change in C2-C7 lordosis positively correlated with a change in C7-SVA and C1-SVA $(\mathrm{r}=0.37, \mathrm{P}<0.005$, and $\mathrm{r}=0.312, \mathrm{p}<0.05$ respectively $)$.

\section{Conclusions}

Multilevel ACDF significantly increases and maintains both segmental and global cervical lordosis up to 6 months after surgery. Increasing C2-C7 global lordosis is correlated with increasing positive sagittal vertical axis. Level of evidence: IV.

CERVICAL SPINE

KEYWORDS: LORDOSIS, CERVICAL, ALIGNMENT, ACDF, SAGITTAL VERTICAL AXIS, ANTERIOR CERVICAL DISCECTOMY AND FUSION, MULTILEVEL VOLUME 11 ISSUE 2 DOI: 10.14444/4013 PAGES $91-98$

\section{Introduction}

Overall spinal sagittal alignment-spinal tilt in the anterior posterior dimension - is determined by the delicate configuration of the four sagittal plane curves: the two kyphotic thoracic and sacral curves, and the two lordotic lumbar and cervical curves. ${ }^{1}$ While our understanding of the mechanical interplay between these spinal segments is still growing, alterations in the alignment or relationship between these curves can have profound impact on load biomechanics, balance, and pain. Overall spinal sagittal alignment is represented by the sagittal vertical axis (SVA), which is the distance from the posterior superior corner of the sacrum to a plumb line from either $\mathrm{C} 1$ (centroid of the $\mathrm{C} 2$ vertebra) or $\mathrm{C} 7$ on a lateral full-length radiograph. Neutral sagittal alignment C7-SVA is highly conserved in normal adults within $\pm 2.5 \mathrm{~cm}$ of the posterior superior corner of the sacrum. ${ }^{2}$ Anterior offset of the C7-SVA $>5 \mathrm{~cm}$ has 
been linked with increasing pain and disability.

In the cervical spine normal sagittal alignment is variable, but typically maintained at $20-35^{\circ}$ lordosis as measured by the Cobb angle between the superior endplate of $\mathrm{C} 2$ to the inferior endplate of $\mathrm{C} 7 .{ }^{6}$ Abnormal kyphosis in the cervical spine increases cantilever loads from the center of gravity of the head resulting in an abnormal stress environment within the spine. ${ }^{7,8}$ Chavanne et al. showed in their cadaveric study that increasing kyphosis results in increased intramedullary pressure in the spinal cord. ${ }^{9}$ Moreover, Shimizu et al showed that progressive kyphosis resulted in demyelination and neuronal loss in a animal model. ${ }^{10}$ In clinical studies, increasing kyphotic alignment of the cervical spine has been correlated with worse patient outcomes. ${ }^{11-13}$ For this reason, restoration of neutral cervical lordosis is desired in cervical degenerative surgery. ${ }^{14}$

The interplay between spinal segments is complex, but there is increasing agreement that fusion of one segment of the spine leads to reciprocal changes in other segments. ${ }^{15}$ Klineberg et al reported reciprocal changes between the thoracic and lumbar spine with increasing lumbar lordosis corresponding with increased thoracic kyphosis and in a separate paper that reduction of thoracic kyphosis reduces lordosis.16 While anterior cervical plating has been previously shown to increase and maintain cervical lordosis in single and multilevel degenerative disease, ${ }^{17,18}$ there have been no studies assessing the impact of increasing cervical lordosis on overall spinal alignment. In the present study we add to the body of evidence supporting the restoration and maintenance of cervical lordosis by using a multilevel ACDF procedure and analyze the impact of increasing cervical lordosis on overall spinal sagittal alignment.

\section{Methods}

Institutional ethical board review was granted and the study initiated in May of 2014. Patients who had undergone multilevel ACDF ( $\geq 3$ levels) by senior authors (J.O. and G. C.) between 2013 and 2014 were reviewed retrospectively. Patients who were adults ( $\geq 18$ years age) and had a diagnosis of central stenosis with myelopathy or myeloradiculopathy who had failed conservative treatment were included. Patients were excluded if they lacked radiographic follow up (4 weeks, 10 weeks and 6 months).

\section{Procedure}

Two ACGME accredited spine fellowship-trained orthopaedic surgeons performed multilevel ACDF consistent with Smith-Robinson techniques. Anterior decompression was performed removing all disc material and posterior osteophytes followed by the insertion of a trapezoidal interbody allograft device. This process was repeated for subsequent levels. Finally a lordotic anterior plate was then selected and fixed to the cervical spine with screws. Implants consisted of: lordotic cortico-cancellous interbody devices produced by MTF/DePuy Synthes (West Chester, PA) with rigid anterior plate fixation by Globus Medical (Audubon, PA).

\section{Measurement technique}

Lateral cervical radiographs were all taken in identical settings with a set source-to-image-distance (SID) of 72". The patient stood in a comfortable position resting the left shoulder against the x-ray bucky and looking ahead at a marker, while keeping their chin parallel to the floor.

Lateral full length 36 " scoliosis films were obtained again at $72^{\prime \prime}$ SID with the arms crossed in front of the patient (elbows flexed to $45^{\circ}$ and fingers on the opposite elbow) and the left shoulder resting on the x-ray bucky. The patient looked ahead at a marker and kept their chin parallel to the floor.

Patient radiographs were reviewed from the following time points: preoperative and postoperative 4 weeks, 10 weeks and 6 months.

Regional cervical sagittal alignment was measured using the widely used Cobb C2-C7 method, which has been shown to have excellent intra and interobserver reliability. ${ }^{19,20}$ We measured the angle formed between the inferior end plate of $\mathrm{C} 2$ and the superior end plate of $\mathrm{C} 7$ for global analysis of cervical alignment. Local sagittal alignment was measured from the superior endplate of the highest to the inferior endplate of the lowest surgical vertebrae. Sagittal vertical axis (SVA) was measured at two time points: 
preoperative and postoperative 4 weeks. The SVA was performed by taking the distance of a plumb line dropped from the centroid of C2 (C1-level equivalent) and the center of the $\mathrm{C} 7$ vertebral body to the most posterior superior aspect of the sacral promontory (Figure 1 and Figure 2).

\section{Analysis}

Measurements were performed by two orthopaedic residents (Y. K. and A. L.) as well as a fellowshiptrained musculoskeletal radiologist (E. L.). All measurements were performed twice and the mean of the

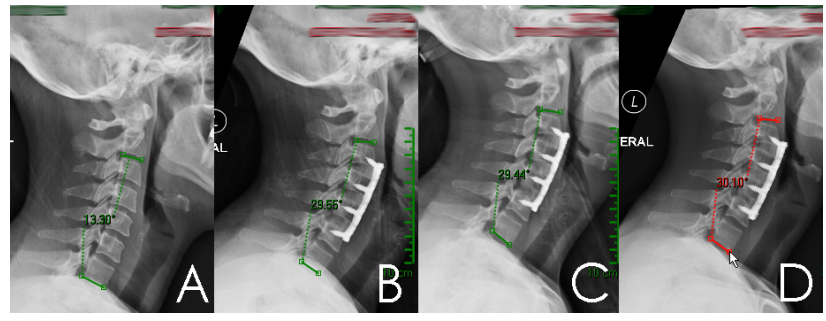

Fig. 1. Case Example: Lateral Cervical $x$-rays obtained at Pre-op (A), 4 weeks (B), 10 weeks (C), and 6 months (D) showing increase in C2-C7 lordosis from $13^{\circ}$, to $29^{\circ}, 29^{\circ}$ and $30^{\circ}$ respectively.

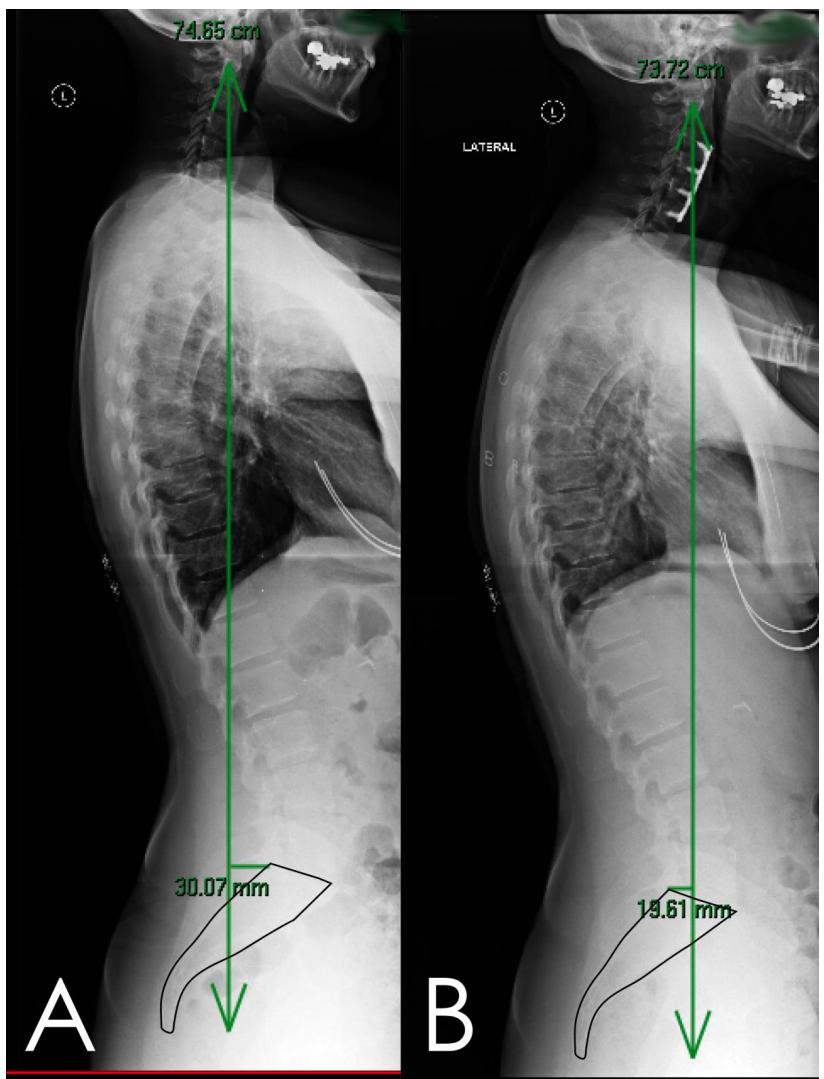

Fig. 2. Case example continued: Lateral full 36 inch scoliosis films taken at pre-op (B) and 4 weeks post op (A) demonstrating increase in sagittal vertical axis from $-30 \mathrm{~mm}$ to $19 \mathrm{~mm}$. two readings was used as a final measurement. For correlation and regression analysis, all readings from the three reviewers were averaged.

\section{Statistics}

All statistics were performed using SPSS version 23.0 (IBM). Summary statistics were calculated for demographic and radiographic measurements. Interobserver reliability was verified using the interclass correlation statistic. For the analysis of global and segmental cervical lordosis, means from each time point were compared using a repeated-measures ANOVA. For analysis of sagittal vertical axis, a paired sample t-test was selected to compare preand post operative means. P-values $<0.05$ were considered statistically significant. The Pearson correlation coefficient was used toassess the relationship between global cervical lordosis and sagittal vertical axis. Linear regression was used to predict the change in SVA based on change in cervical lordosis.

\section{Results}

\section{Demographic Data}

We identified 69 patients meeting our inclusion criteria (47 female). The average age was 57 years (range 33-81). A summary of patient demographics is available in Table 1 . The majority of patients underwent four level ACDF $(n=46)$, followed by three level $\operatorname{ACDF}(n=23)$. For analysis of sagittal vertical axis, 58 patients within the previous group who had also had full-length 36 " scoliosis films available for review. The average age was 56.72 (range 33-81). The summary of patient demographics is available in Table 2. The majority of patients underwent four level ACDF ( $\mathrm{n}=39)$, followed by three level ACDF $(\mathrm{n}=19)$.

\section{Reliability analysis}

We demonstrated good (ICC >0.8) to excellent (ICC $>0.9$ ) interater reliability for all measured radiographic variables. For measurement of global lordosis ICC was 0.96 (95\% CI 0.96, 0.97). For measurement of segmental lordosis interrater reliability was good with ICC of 0.89 (95\% CI 0.85, 0.93). Interrater reliability was excellent for C1-SVA measurement with an ICC of 0.91 (95\% CI 0.90, 0.93). Interrater reliability was excellent for C2-C7 SVA measurement with an 
ICC of 0.94 (95\% CI 0.92, 0.95).

\section{Cervical Lordosis}

The mean global lordosis measured at each time point was as follows: preoperative $10.26^{\circ}(95 \% \mathrm{CI}$ $\left.9.16^{\circ}, 11.37^{\circ}\right), 4$ weeks $19.45^{\circ}\left(95 \%\right.$ CI $18.53^{\circ}$, $\left.20.35^{\circ}\right), 10$ weeks $19.81\left(95 \% \mathrm{CI} 19.96,20.65^{\circ}\right)$ and 6 months $19.34\left(95 \% \mathrm{CI} 18.47^{\circ}, 20.21^{\circ}\right)$ (Figure 3). A repeated measures ANOVA showed a statistically significant difference in the means of the pre-op time point and all post operative time points, $\mathrm{F}=316$, $\mathrm{p}<0005$. Pairwise analysis showed the postoperative time points were not significantly different between 4 wks to 10 wks and 10 wks to 6 months $(\mathrm{p}=0.143$, and $\mathrm{p}=0.113$ respectively). Thus the null hypothesis was rejected.

The mean segmental lordosis measured at each time point was as follows: preoperative $8.22^{\circ}$ (95\% CI $\left.7.2^{\circ}, 9.23^{\circ}\right), 4$ weeks $20.35^{\circ}\left(95 \% \mathrm{CI} 19.5^{\circ}, 21.21^{\circ}\right)$, 10 weeks $20.3^{\circ}\left(95 \% \mathrm{CI} 19.46^{\circ}, 21.12^{\circ}\right)$, and 6 months $19.57^{\circ}\left(95 \% \mathrm{CI} 18.68^{\circ}, 20.45^{\circ}\right)$. A repeated measures ANOVA showed a statistically significant difference in the means of the preoperative time

Table 1. Study demographics for cervical alignment.

\begin{tabular}{|l|r|}
\hline Demographic & \\
\hline Mean Age & 56 yrs \\
\hline Sex & 47 female \\
\hline Smoking & $\mathrm{N}=32$ \\
\hline Mean Weight & 185.1 Lbs \\
\hline Mean Height & 64.9 inches \\
\hline Levels Fused & 4 levels, N=46 \\
& 3 Levels, N=23 \\
\hline
\end{tabular}

Table 2. Study demographics for full-length sagittal vertical axis.

\begin{tabular}{|l|r|}
\hline Demographic & 56 yrs \\
\hline Mean Age & 39 female, 19 Male \\
\hline Sex & $\mathrm{N}=28$ \\
\hline Smoking & 182.1 Lbs \\
\hline Mean Weight & 65.1 inches \\
\hline Mean Height & 4 levels, N=39 \\
3 Levels, N=19 \\
\hline Levels Fused
\end{tabular}

point and all post operative time points, $\mathrm{F}=454$, $\mathrm{P}<0.0005$. Pair wise analysis showed the postoperative time points were not significantly different between 4 weeks to 10 weeks, and 10 weeks to 6 months ( $\mathrm{p}=1.00$ and $\mathrm{p}=0.077$ respectively).

\section{Sagittal Vertical Axis}

The mean preoperative C2-C7 SVA was $12.04 \mathrm{~mm}$ $( \pm 2.55 \mathrm{~mm})$ and the mean postoperative $\mathrm{C} 2$-C7 SVA was $27.49 \mathrm{~mm}( \pm 2.24 \mathrm{~mm})$, and the mean difference was $15.49( \pm 1.62 \mathrm{~mm})$ (Figure 4$)$. A paired sample ttest showed the two means were significantly different $(t=-9.48, p<0.0005)$. Thus the conclusion was made that there was a significant increase in C2-C7 SVA.

The mean preoperative C7-SVA was $-1.93 \mathrm{~mm}$ $( \pm 2.19 \mathrm{~mm})$ and the mean postoperative C7-SVA was $8.67 \mathrm{~mm}( \pm 2.04 \mathrm{~mm})$, and the mean difference was $10.59( \pm 1.45 \mathrm{~mm})$. A paired sample $\mathrm{t}$-test showed the two means were significantly different $(\mathrm{t}=-7.27$, $\mathrm{p}<0.0005)$. Thus, there was a significant increase in

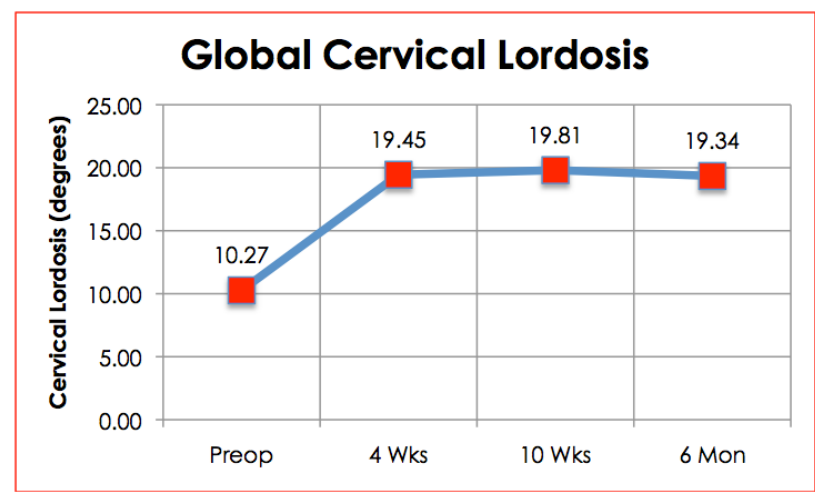

Fig. 3. Line chart of the average degree of cervical lordosis measured at four time points (preoperative, 4 weeks, 10 weeks and 6 months postoperative).

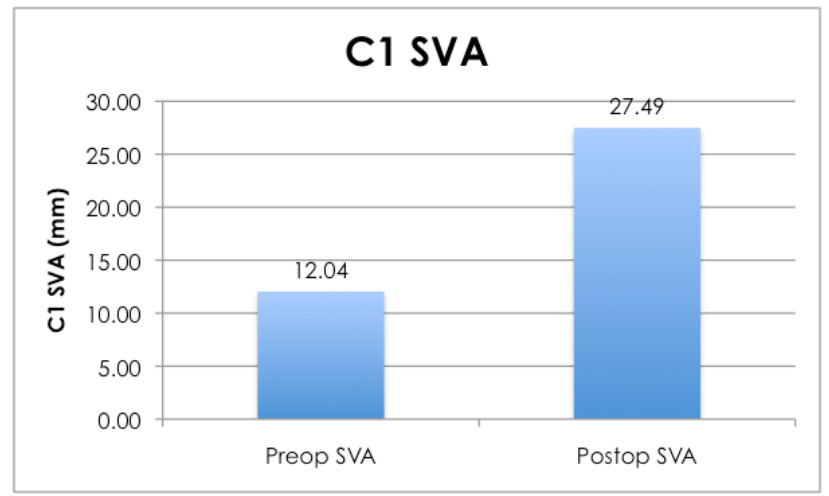

Fig. 4. Bar graph showing the pre- and postoperative C1-SVA means. 
C7-SVA.

Global Lordosis to Sagittal Vertical Axis Correlation For the subset of patients who had full length scoliosis films correlation analysis was performed. The mean change in global lordosis from pre- to postoperative was $9.28^{\circ}( \pm 0.96)$. The mean change in C7-SVA from pre- to postoperative was $10.59 \mathrm{~mm}$ $( \pm 3.28)$. The mean change in C2-C7 SVA from preto postoperative was $15.44 \mathrm{~mm}( \pm 3.67)$. The change in C2-C7 lordosis had a positive correlation with both the change in C7-SVA $(r=0.37, \mathrm{P}<0.005)$ and the change in C2-C7 SVA $(r=0.312, \mathrm{p}<0.05)$. Linear regression analysis with change in $\mathrm{C} 2-\mathrm{C} 7$ lordosis as the independent variable and change in C7-SVA and C2-C7 SVA as the dependent variables revealed significant association $\left(\mathrm{r}^{2}=0.135(\mathrm{p}<0.005)\right.$ and $\mathrm{r}^{2}=$ $0.10(\mathrm{p}<0.05)$ respectively (Figure 5).

\section{Discussion}

Cervical lordosis is derived from both primary (developed in utero) and secondary (resulting from environmental forces) factors. 21 Loss of natural lordosis has been related to pathological changes in the spinal cord. ${ }^{9,10}$ The largest amount of regional variation in tolerated sagittal alignment occurs in the cervical spine. 22 Gore et al reported the $\mathrm{C} 2-\mathrm{C} 7$ angle in 200 asymptomatic patients as measuring between $16^{\circ}$ and $27^{\circ}$ depending on age. ${ }^{6}$ In an elegant synthesis of 12 studies of cervical alignment, Kuntz et al reported a pooled estimate of $\mathrm{C} 2-\mathrm{C} 7$ cervical lordosis as $17^{\circ}$ with a variability of $-11^{\circ}$ to $+45^{\circ}$ across studies. Sev-

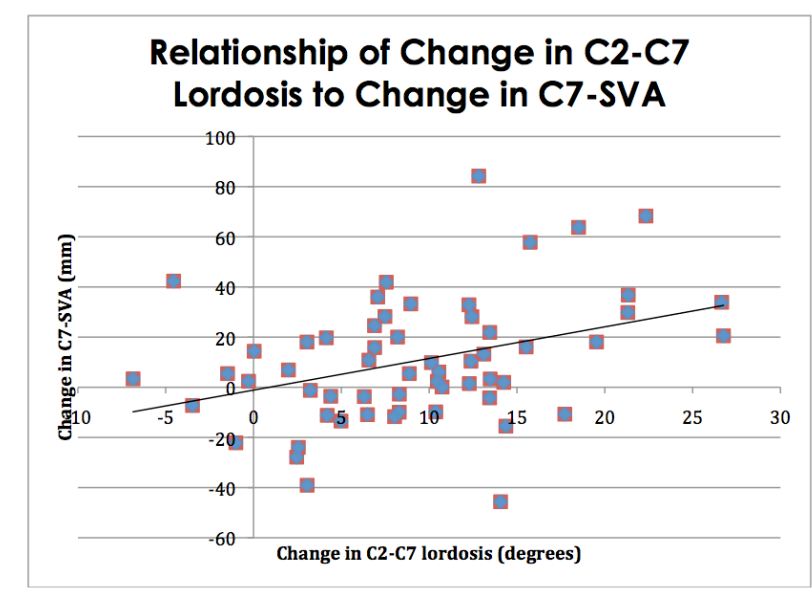

Fig. 5. Scatter plot and regression analysis of change in C2-C7 Lordosis vs. change in C7-SVA in pre- to postoperative measurements. eral studies have correlated both pre- and postoperative cervical lordosis with improved clinical outcome scores. ${ }^{11-13}$,23Tang et al. showed that patients who had loss of lordosis as measured by increasing C2-C7 SVA had worse outcomes on Neck Disability Index (NDI) and SF-36 instruments. In their prospective randomized study comparing parallel to lordotic interbody devices in ACDF, Villlavicencio et al showed that patients who had increased lordotic segmental sagittal alignment had a higher degree of clinical improvement as measured by the NDI and SF-36 instruments. Recently in their retrospective study, Iyer et al showed that negative correlation between C2-C7 SVA and NDI. While not directly correlated with clinical outcome, Okada et al showed that nonlordotic configuration of the cervical spine was associated with accelerated degenerative changes (i.e. posterior disk protrusion and disc space narrowing). 24

While there is significant variability in what can be considered normal cervical alignment, standing sagittal vertical axis is maintained within a much more narrow physiologic range. Deviations from this can inhibit individuals ability for upright posture and ambulation. ${ }^{3}$ Typically the normal C7-SVA is maintained within $\pm 2.5 \mathrm{~cm}$ to maintain balance and horizontal gaze. The reciprocal changes in one spinal region with the alteration of another have long been recognized. ${ }^{24,25}$ Previous studies have correlated increasing SVA with increases in cervical lordosis. ${ }^{15,27}$ In their multicenter retrospective study Smith et al. studied patients with C7-SVA $>5 \mathrm{~cm}$ who underwent lumbar pedicle subtraction osteotomy and showed that as SVA decreased there was a relaxation in cervical hyperlordosis. Moreover, increasing SVA has been correlated with poor clinical outcomes in multiple studies. ${ }^{3,5,27}$

In the present study we showed significant increases in cervical lordosis after a multilevel ACDF procedure(Figure 6). In addition, we showed a weak $\left(\mathrm{r}^{2}=0.1\right)$ but statistically significant $(\mathrm{p}<0.05)$ correlation between increasing cervical lordosis and a positive shift in the vertical alignment of the spine (SVA). Based on this analysis, rougnly $10 \%$ of sagittal vertical axis change can be reliably explained by the change in cervical lordosis. While the governance of sagittal 
vertical balance is complex and likely multifactorial, it seems reasonable to conclude from this study that the change in cervical lordosis plays at least a partial role in the alteration of sagittal alignment. As this study is purely radiographic, the clinical implications of this relationship were not determined. Future studies should examine outcome measures with relation to overall change in cervical lordosis and its relationship with SVA.

In the present study we hypothesized that multilevel ACDF would increase cervical lordotic alignment but the increase in SVA was surprising. This increase also seems to fit the model of the positive correlation between cervical lordosis and SVA to maintain physiologic horizontal gaze discussed in previous studies.

Although analysis of the lumbar segment was not the purpose of this study, we suspect the compensatory increase in SVA resulted from a relaxation in lumbar lordosis and is reciprocal to the model proposed by Smith.

Limitations to this study include the following. First, this study is retrospective in nature and no comparison groups were used. Furthermore there are poten-
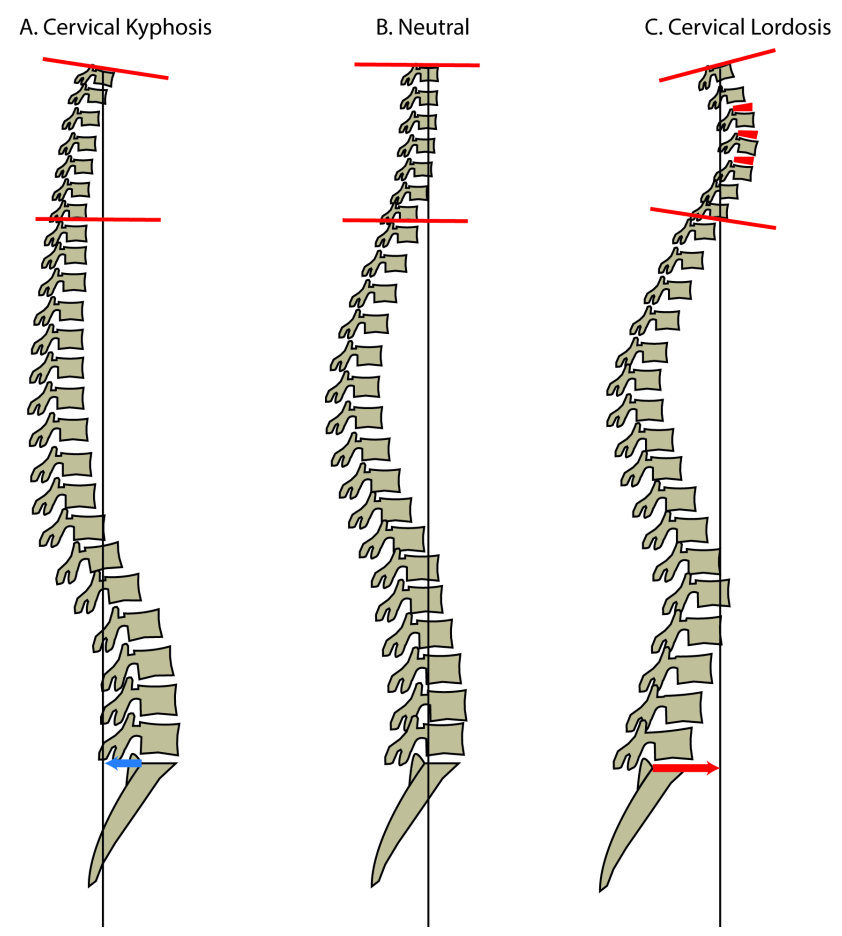

Fig. 6. Diagram of Sagittal Vertical Axis (SVA, black line) shift with regards to increasing cervical lordosis (Cobb angle measured by red lines). As Cervical Lordosis increased from A to C, SVA also increases (blue and red arrow). tial differences in surgical technique performed between the two surgeons, although both surgeons performed each surgery jointly. Additionally it should be noted that this study had a high predominance of female patients $(2: 1)$, which is contradictory to reported sex ratios for spondylolytic myelopathy (typically male to female $3: 2) .{ }^{28}$ We suspect this is due to regional variation and is unlikely to affect our results, as there is minimal difference in baseline cervical lordosis between males and females. ${ }^{6}$ Finally, this study offers only 6 months of clinical follow up with no clinical outcomes to gauge treatment efficacy. While we show a significant increase in lordosis, follow up studies should be directed at measuring clinical outcome scores and fusion rates.

\section{Conclusions}

In this paper we show that multilevel ACDF with lordotic interbody devices significantly increases and maintains both global and segmental cervical lordosis. In addition we show that increasing cervical lordosis can have the secondary effect of increasing sagittal vertical balance, the clinical ramifications of which are currently unknown. Future studies should examine the clinical implications of increasing lordosis and if there is an optimal amount of correction for best results.

\section{References}

1. Herkowitz H, Garfin SR, Eismont FJ, Bell G, Balderston R. Rothman-Simeone The Spine, 6th Edition. In: Rothman-Simeone The Spine, 6th Edition.

2. Jackson RP, McManus ACR. Radiographic Analysis of Sagittal Plane Alignment and Balance in Standing Volunteers and Patients with Low Back Pain Matched for Age, Sex, and Size: A Prospective Controlled Clinical Study. Spine. 1994 Jul;19(14):1611-8.

3. Glassman SD, Berven S, Bridwell K, Horton W, Dimar JR. Correlation of radiographic parameters and clinical symptoms in adult scoliosis. Spine. 2005;30(6):682-688.

4. Schwab F, Farcy J-P, Bridwell K, Berven S, Glassman S, Harrast J, et al. A clinical impact classi- 
fication of scoliosis in the adult. Spine. 2006 Aug 15;31(18):2109-14.

5. Schwab F, Patel A, Ungar B, Farcy J-P, Lafage V. Adult spinal deformity - postoperative standing imbalance: how much can you tolerate? An overview of key parameters in assessing alignment and planning corrective surgery. Spine. 2010;35(25):2224-2231.

6. Gore DR, Sepic SB, Gardner GM. Roentgenographic findings of the cervical spine in asymptomatic people. Spine. 1986 Aug;11(6):521-4.

7. Beier G, Schuck M, Schuller E, Spann W. Determination of Physical Data of the Head I. Center of Gravity and Moments of Inertia of Human Heads. [Internet]. [cited 2013 Dec 8]. Available from: http://0-thejns.org.opac.uthsc.edu/doi/pdf/ 10.3171/2013.4.SPINE12838

8. Scheer JK, Tang JA, Smith JS, Acosta FL Jr, Protopsaltis TS, Blondel B, et al. Cervical spine alignment, sagittal deformity, and clinical implications: a review. J Neurosurg Spine. 2013 Aug;19(2):141-59. 9. Chavanne A, Pettigrew DB, Holtz JR, Dollin N, Kuntz C. Spinal Cord Intramedullary Pressure in Cervical Kyphotic Deformity: A Cadaveric Study. Spine. 2011 Sep;36(20):1619-26.

10. Shimizu K, Nakamura M, Nishikawa Y, Hijikata S, Chiba K, Toyama Y. Spinal Kyphosis Causes Demyelination and Neuronal Loss in the Spinal Cord: A New Model of Kyphotic Deformity Using Juvenile Japanese Small Game Fowls. Spine. 2005 Nov;30(21):2388-92.

11. Villavicencio AT, Babuska JM, Ashton A, Busch E, Roeca C, Nelson EL, et al. Prospective, randomized, double-blind clinical study evaluating the correlation of clinical outcomes and cervical sagittal alignment. Neurosurgery. 2011 May;68(5):1309-1316; discussion 1316.

12. Tang JA, Scheer JK, Smith JS, Deviren V, Bess $S$, Hart RA, et al. The impact of standing regional cervical sagittal alignment on outcomes in posterior cervical fusion surgery. Neurosurgery. 2012 Sep;71(3):662-669; discussion 669.

13. Iyer S, Nemani VM, Nguyen J, Elysee J, Burapachaisri A, Ames CP, et al. Impact of Cervical Sagittal Alignment Parameters on Neck Disability: SPINE. 2016 Mar;41(5):371-7.

14. Ferch RD, Shad A, Cadoux-Hudson TAD, Teddy PJ. Anterior correction of cervical kyphotic defor- mity: effects on myelopathy, neck pain, and sagittal alignment. J Neurosurg. 2004 Jan;100(1 Suppl Spine):13-9.

15. Smith JS, Shaffrey CI, Lafage V, Blondel B, Schwab F, Hostin R, et al. Spontaneous improvement of cervical alignment after correction of global sagittal balance following pedicle subtraction osteotomy. J Neurosurg Spine. 2012 Oct;17(4):300-7. 16. Klineberg E, Schwab F, Ames C, Hostin R, Bess $\mathrm{S}$, Smith JS, et al. Acute Reciprocal Changes Distant from the Site of Spinal Osteotomies Affect Global Postoperative Alignment. Adv Orthop.

2011;2011:1-7.

17. Katsuura A, Hukuda S, Imanaka T, Miyamoto $\mathrm{K}$, Kanemoto M. Anterior cervical plate used in degenerative disease can maintain cervical lordosis. J Spinal Disord. 1996 Dec;9(6):470-6.

18. Troyanovich SJ, Stroink AR, Kattner KA, Dornan WA, Gubina I. Does anterior plating maintain cervical lordosis versus conventional fusion techniques? A retrospective analysis of patients receiving single-level fusions. J Spinal Disord Tech. 2002 Feb;15(1):69-74.

19. Harrison DE, Harrison DD, Cailliet R, Troyanovich SJ, Janik TJ, Holland B. Cobb method or Harrison posterior tangent method: which to choose for lateral cervical radiographic analysis. Spine. 2000 Aug 15;25(16):2072-8.

20. Ohara A, Miyamoto K, Naganawa T, Matsumoto K, Shimizu K. Reliabilities of and correlations among five standard methods of assessing the sagittal alignment of the cervical spine. Spine. 2006 Oct 15;31(22):2585-2591; discussion 2592.

21. Bagnall KM, Harris PF, Jones PR. A radiographic study of the human fetal spine. 1. The development of the secondary cervical curvature. J Anat. 1977;123(Pt 3):777.

22. Kuntz C 4th, Levin LS, Ondra SL, Shaffrey CI, Morgan CJ. Neutral upright sagittal spinal alignment from the occiput to the pelvis in asymptomatic adults: a review and resynthesis of the literature. J Neurosurg Spine. 2007 Feb;6(2):104-12.

23. Kwon B, Kim DH, Marvin A, Jenis LG. Outcomes following anterior cervical discectomy and fusion: the role of interbody disc height, angulation, and spinous process distance. J Spinal Disord Tech. 2005 Aug;18(4):304-8. 
24. Okada E, Matsumoto M, Ichihara D, Chiba K, Toyama Y, Fujiwara H, et al. Does the sagittal alignment of the cervical spine have an impact on disk degeneration? Minimum 10-year follow-up of asymptomatic volunteers. Eur Spine J Off Publ Eur Spine Soc Eur Spinal Deform Soc Eur Sect Cerv Spine Res Soc. 2009 Nov;18(11):1644-51.

25. Lafage V, Schwab F, Skalli W, Hawkinson N, Gagey P-M, Ondra S, et al. Standing balance and sagittal plane spinal deformity: analysis of spinopelvic and gravity line parameters. Spine. 2008 Jun 15;33(14):1572-8.

26. Ames CP, Blondel B, Scheer JK, Schwab FJ, Le Huec J-C, Massicotte EM, et al. Cervical radiographical alignment: comprehensive assessment techniques and potential importance in cervical myelopathy. Spine. 2013 Oct 15;38(22 Suppl 1):S149-160.

27. Glassman SD, Bridwell K, Dimar JR, Horton W, Berven S, Schwab F. The impact of positive sagittal balance in adult spinal deformity. Spine.

2005;30(18):2024-2029.
28. Tracy JA, Bartleson JD. Cervical Spondylotic Myelopathy: The Neurologist. 2010

May;16(3):176-87.

\section{COI \& Disclosures}

The authors declare no relevant financial disclosures.

\section{Corresponding Author}

Yoshihiro Katsuura, Department of Orthopaedic Surgery, University of Tennessee at Chattanooga, 979 East Third St. Suite 202, Chattanooga, TN 37403.yoshikatsuura@gmail.com.

Published 5 April 2017.

This manuscript is generously published free of charge by ISASS, the International Society for the Advancement of Spine Surgery. Copyright $\odot 2017$ ISASS. To see more or order reprints or permissions, see http://ijssurgery.com. 